staudenbeete oder für den eher „aquaphilen“ Gartenfreund mit Wildpflanzen bestückte Teiche sind attraktive Umsetzungsformen.

Bevor man eigene Ideen für den eigenen naturnahen Garten entwickelt, sollte man sich den vorliegenden Gestaltungs- und Bepflanzungsführer zu Gemüte führen. Er gibt gut umsetzbare Anregungen und Anleitungen. Darunter sind auch eindrucksvolle Fotos von nahezu 200 zur Auswahl stehenden Pflanzenarten. Diese werden anhand kurzer Porträts bezüglich ihrer Eignung für den jeweiligen Lebensraum beschrieben.

Der reich illustrierte Band ist weit mehr als eine Gebrauchsanweisung für (angehende) Gartenliebhaber. Mit einem Füllhorn an Sachinformationen motiviert er, sich einfach mal an solch eine Aufgabe mutig heranzuwagen. Das Buch erhielt 2017 den Deutschen Gartenbuchpreis in der Kategorie Ratgeber (2. Platz).

Christiane Högermann

\title{
Interview mit BrUno P. KREMER
}

\author{
von Christiane Högermann
}

Dr. Bruno P. Kremer lehrte im Fach Biologie und ihre Didaktik an der Universität zu Köln, war viele Jahre lang Mitglied im Kuratorium der Zeitschrift „Biologie in unserer Zeit" tätig und hat als wissenschaftlicher Gutachter gearbeitet. Seine disziplinübergreifenden Werke zeichnen sich dadurch aus, dass sie die Biologie in lesenswerter Form darstellen und auch zuweilen unterhaltsame ironische Züge mitschwingen lassen.

C. H: Herr Kremer, wie gelingt es Ihnen, Ihr Markenzeichen, komplizierte biologische bzw. naturwissenschaftliche Sachverhalte auf ein lesenswert wissenschaftliches Niveau herunterzubrechen, umzusetzen, ohne in den allzu populärwissenschaftlichen Bereich zu geraten?

B. K.:Schon zu Schüler- und Studentenzeiten war ich journalistisch tätig und habe durch mancherlei Hinweise erfahrener älterer Kollegen, die meine Texte glücklicherweise erbarmungslos redigiert haben, hinsichtlich der Ausdrucksweise unglaublich viel gelernt. In meinem späteren Berufsleben an der Universität zu Köln habe ich Lehramtsstudierende fachwissenschaftlich ausgebildet. Wenn ich in meinen Seminaren, Vorlesungen oder Übungen bei der Besprechung irgendwelcher naturwissenschaftlicher Sachverhalte bei meiner Zuhörerschaft nach den ersten Minuten „gläserne Augen“ bemerkte, wusste ich: Das war's wohl noch nicht - hier gibt es offenkundig Nachrüstungsbedarf.
Im Laufe von Jahren (oder besser: Jahrzehnten) trainiert das ungemein. Mit der diesbezüglichen Wahrnehmung durch meine Studierenden (nachlesbar auf der Internetplattform www.meinprof. de) bin ich äußerst zufrieden.

C. H.: Wie gehen Sie mit Kritik zu Ihrer besonderen Art der Darstellung um?

B. K.: Bei meinen vielen Veröffentlichungen habe ich glücklicherweise noch nie einen Totalverriss hinnehmen müssen. Es gab hin und wieder natürlich schon mal leicht kritische Töne, aber das Gesamtecho (auch in den diversen Internet-Rezensionen) bestätigt mich in meinem Ansatz total.

C. H.: Gibt es Themen, die Ihnen besonders am Herzen liegen, über die Sie also besonders gerne schreiben? Wenn ja, welche sind es?

B. P.: Mein Hauptanliegen ist es, meine Mitwelt aus den unsäglichen virtuellen Sphären wieder für ein echtes und originales, vor allem verstehendes Naturerleben zurückzugewinnen. Die uns umgebende Natur ist - selbst inmitten der Großstadt - in ihren diversen Facetten so total faszinierend, dass es absolut schade und geradezu unverzeihlich wäre, sich diese Erlebnisqualitäten nicht zu sichern. Zudem ist der praktische Naturschutz vor der eigenen Haustür mein besonderes Anliegen. Ich befinde mich damit im absoluten Konsens 
mit allen großen Naturschutzverbänden, deren Mitglied ich natürlich bin. Meine in Arbeit befindlichen oder jüngst erschienenen Projekte thematisieren genau diese Zielachse.

C. H.: Bitte formulieren sie eine Botschaft, die Sie dem autodidaktischen, aber auch streng wissenschaftlich orientierten Leser mitgeben möchten.

B. K.: Die uns umgebende Natur ist ein einzigartig großartiger Erlebnisraum. Allerdings: Schon GoETHe hat zutreffenderweise formuliert: „Man sieht nur, was man weiß“. Man muss sich also aktiv mit seinem Umfeld beschäftigen. Es gibt überall in Deutschland jede Menge lokaler oder regionaler Vereinigungen, die dazu ein überaus reiches und wahrnehmenswertes Veranstaltungsangebot bereithalten. Eine unbedingt empfehlenswerte Blickachse sind die in vielen größeren Städten angesiedelten „Mikroskopischen Gesellschaften“. Das Eindringen in den besonderen Formenzauber der ganz kleinen Welten ist unverhältnismäßig einfach und durch andere Naturerfahrungen kaum zu toppen.

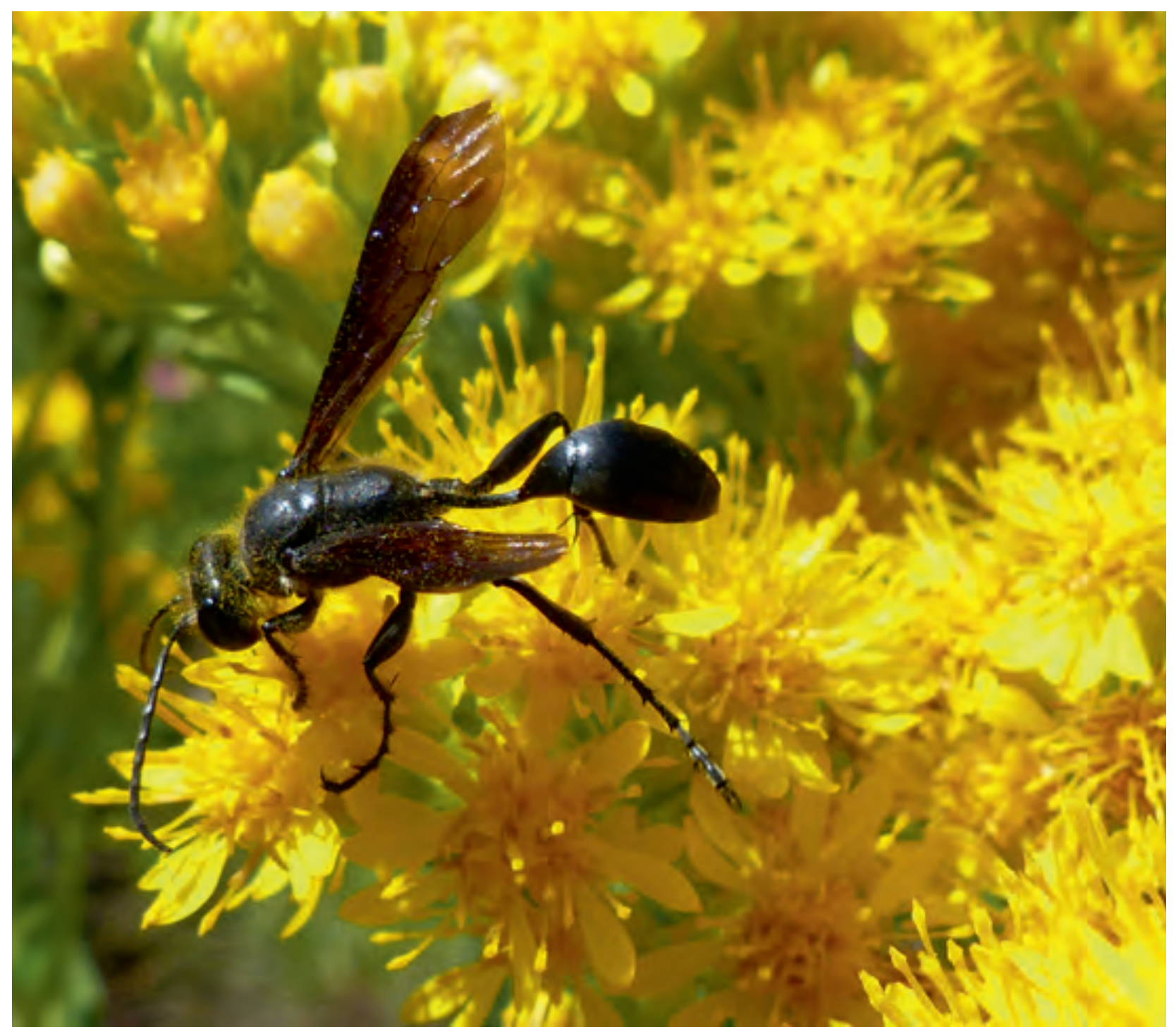

Abb. 1: In der arten- und blütenreichen Steppenanlage des Palmengartens sind auch viele Insekten zu finden. Die Grabwespe Isodontia mexicana fällt durch ihren lang gestielten Hinterleib auf. Ursprünglich stammt sie aus Nord- und Mittelamerika. Seit den 1960er Jahren ist sie als Neozoon auch in Süd-Frankreich anzutreffen. Von hier aus breitet sie sich immer weiter nach Norden aus. In Deutschland wurde Sie erstmals Ende der 1990er Jahre gesichtet. (Foto: H. STEInecke) 